(6) Increased alveolar carbon dioxide pressure."

Whether we have much faith in his predictions or not, it must be agreed that Mr McCreery has faced up to a major problem facing parapsychologists. It remains for him to test his predictions and report the result. He must, however, pay more attention to those pitfalls encountered by previous ESP investigators than he has done in the first part of his book.

C. E. M. HANSEI

1 Munsterburg, H., Metropolitan Magazine (February 1910).

2 Miller, D. S., Seience, LXXVII (1910).

\section{MODEST PHYSICIST'S THOUGHTS}

\section{Symmetries and Relections}

Scientific Essays. By Eugene P. Wigner. Pp. viii +280 . (Bloomington and London: Indiana University Press, 1967.) $\$ 7.50 ; 56 s$.

This volume is a collection of addresses and essays by Professor Eugene P. Wigner, Nobel Laureate in physics. A wide range of topics is covered, including discussions on the meaning and interpretation of the basic concepts of physies, reminiscences of the first man-made nuclear chain reaction in Chicago in 1942, biographies of Enrico Fermi and John von Neumann, and evaluation of the problems facing humanity in a nuclear age. In all a fascinating collection, which will appeal to a much wider audience than merely physicists. On the whole the level is nonspecialist, and these essays and talks are concerned more with aims, motives and meaning of science than with details of the author's own field, theoretical physics. Indeed, copies of this book could well be included in the libraries of high schools.

The reader may be interested in a quotation from Wigner's J. F. Carlson lecture, which forms the final chapter, "The Growth of Science-Its Promise and Its Dangers": "Already, we have more trouble in controlling the spread of dangerous and of habit-forming drugs than of nuclear weapons, and they have caused more unhappiness than the latter." GRAHAM DERRICK

\section{PROSPECT OF EARTH}

\section{Viewing Weather from Space}

By E. C. Barrett. (Longmans' Geography Paperbacks.) Pp. xii $+140+8$ plates. (London : Longmans, Green and Co., Ltd., 1967.) 21s. net.

IT is always useful to see another point of view and in certain fields of scientific endeavour it is extremely helpful to see from another viewing point. This is most true in the study of the Earth's atmosphere, the "ocean of air" drifting around and above us largely unseen if not entirely unperceived. How technology has aided the meteorologist, aeronomer and ionospheric physicist by providing the "topside soundings" is a fascinating story, largely told in press releases and popular articles, but a tale that loses nothing in retelling especially in such a concise and informative way as in Mr. Barrett's slim volume. Viewing Weather from Space is broad in its concept; its writer aims at a fairly general audience and seeks to show how the development of the meteorological satellite has stimulated new methods and revised concepts in the atmospheric sciences. Everyman is hard to please and it is possible that this book will find most favour with students, to whom its size, price and review nature will appeal.

It must be admitted that virtually all of the research in meteorological satellite development, data evaluation and utilization has been performed in the United States while the rest of the world has benefited in terms of improved forecasts. The book perforce is a summary of US experience, but this implies no geographical limitation in scope because most features revealed in satellite pictures are the result of fundamental processes in the free atmosphere. 'This raises the question as to whether those chapters of the book which follow conventional climatological divisions of the atmosphere (the fourth, fifth and sixth chapters, "The General Circulation...", "The Tropical Atmosphere" and "Weather Systems in Temperate Latitudes") represent logical subdivisions or whether it might not have been better to present a framework based on the basic geometric structures which have been revealed by the pictures themselves, for example, vortices, linear features, cellular patterns and so on. Admittedly, it would be more difficult to insert the more basic elements of meteorological theory into this type of framework, but the approach could be considered more appropriate to a book dealing with satellite pictures and their features.

It is the photographs which are the basis for the work, so could not the publisher have avoided binding the plates in the centre of the book? No doubt this represents a saving in production costs, but it is a source of irritation to be faced with the choice of committing them to memory or turning back time after time to find the specific example. Economics probably prevented the author from including more examples, but could he not have substituted some sketch reproductions to illustrate his discussion? The quality of the illustrations is very high, but some of the diagrams are rather aged; thus the hurricane cross-section shows no primary and secondary cells or "hot tower" and the general circulation still has a driven meridional cell in middle latitudes. Forecasting in middle latitudes has been rendered a disservice when Mr Barrett states that in the middle troposphere isobars and isotherms tend to parallel each other, but then medium range forecasts are not mentioned as part of the forecaster's lot. What is important is that the operational value of photographs or nephanalyses is stressed. This brings us to the final point; at the moment the television camera satellite is an exciting new tool, but very soon it will be just another instrumental aid. Whether it will lead research workers to new conclusions about the atmosphere and its mechanisms is very much a matter for debate, but it certainly will excel at its designated task of surveillance and thus improve our synoptic appreciation. Viewing Weather from Space looks to the instrumental advances of the future and performs a service in putting into easily digested perspective the present role of the weather eye in the sky. P. LARSSON

\section{SULPHUR HETEROCYCLICS}

Multi-Sulfur and Sulfur and Oxygen Five- and Sixmembered Heterocycles

By David S. Breslow and Herman Skolnik. Part 1: Pp. xxii + 1-610. Part 2: Pp. xviii +611-1403. (The Chemistry of Heterocyclic Compounds: a Series of Monographs, Vol. 21, Parts 1 and 2.) (New York and London: Interscience Publishers, a Division of John Wiley and Sons, 1966.) 600s.

THE literature of organic sulphur compounds has recently made some notable gains, and the addition of this volume to the well-known Interscience series on heterocyclic compounds provides useful coverage for a hitherto poorly documented area. More than two hundred parent ring systems are encompassed by the title, although many of these have only a small literature, having been only rarely studied for their intrinsic interest.

The two parts of the volume deal respectively with fiveand six-membered rings, and, as might be expected, the major sections in each concern systems containing two hetero-atoms. These include the more familiar 1,2- and 1,3-dithia- and oxathia-heterocycles, and the 1,4-dithianes; sizable chapters are also merited by eyclic sulphite, sulphate and sulphonate esters. A final chapter, curiously unadvertised in the title, is devoted to analogous systems 